\title{
Teaching Theory and Practice to Trainee Translators: Putting Together the Pieces of the Jigsaw Puzzle
}

\author{
Ula Al-Dabbagh \\ University of Petra, Amman, Jordan
}

\begin{abstract}
This paper rests on the assumption that theory and practice should be given equal weight when designing translation courses offered to trainee translators. It, therefore, argues that theory is not merely an embellishment in such courses, but a complementary component to the practical part. The reason underlying this argument is that, without the theoretical input, the translation output is based just on the trainee translators' intuition; an approach that many translator scholars believe cannot be adopted by those wishing to take up translation as a profession. To test this assumption, a multi-level translator training module that incorporates theory and practice has been designed for the "Introduction to Translation" course offered to trainee translators at the University of Petra, Jordan. The implications of such an approach are analyzed by asking these trainee translators to answer a questionnaire whereby they assess the effectiveness of the module taught throughout the semester.
\end{abstract}

Keywords: theory, practice, intuition, trainee translators, multi-level translator training module

\section{Introduction}

The institutional training of translators at the undergraduate university level in Jordan started in the early 1990s to meet the pressing market demand for professional translators. Up until 1990, when the government authorized the establishment of private universities in the country, Jordan University and Yarmouk University were the only two public institutions that offered postgraduate degrees in translation: a diploma in English/Arabic/English translation and an M.A. in English/Arabic/English translation (Shunnaq, 1998). Today, there is a proliferation of universities that offer B.A. degrees in translation with the aim of providing students with the necessary skills and competencies expected of would-be-professional translators.

One of the first private universities that introduced an B.A. program in English/Arabic/English translation is the University of Petra. This academic institution, established in 1991 and which adopts the American credit hour system, offers undergraduate degrees in 24 different specializations, one of which is translation. The B.A. degree in translation is offered by the English Department, and students who enroll in this specialization have attended public and private schools in Jordan and other parts of the world, and have all passed the secondary school certificate (Tawjihi) or its equivalent.

To graduate with an B.A. in English/Arabic/English translation, students have to complete 135 credit hours; of these 93 are offered by the English Department and the remaining 42 hours are university and faculty

Ula Al-Dabbagh, assistant professor, English Department, University of Petra. 
requirements. "Introduction to Translation" is one of the 93 credit hours and is the first compulsory translation course that trains students majoring in this specialization to translate from English into Arabic; therefore, it equips students with the necessary skills needed for the subsequent translation courses.

Students take "Introduction to Translation" in their second year after completing eight departmental compulsory courses that focus on the four language skills, as well as grammar, phonetics, linguistics, and literature, all of which constitute the backbone for the more advanced courses students study in the third and fourth years ${ }^{1}$.

The English-language linguistic competencies of the majority of students who take "Introduction to Translation” range between average and below average; a limited number of students exhibit a high level of linguistic proficiency in English. Many students, however, have a thorough command of the Arabic language. This concoction of linguistic abilities creates the need to design a syllabus that is tailored to meet the needs of these trainee translators; the aim of the proposed syllabus, is first and foremost, to provide trainee translators with a set of guidelines that they can rely on to overcome the problems they encounter when they embark on the actual process of translation. This paper, therefore, introduces a multi-level translator training module which shows that theory and practice have to go hand in hand in such a diversified milieu whereby theory would serve as a firm foundation for the practical component.

\section{Theory and Translator Training: An Overview}

Although the theory versus practice dichotomy in designing translation training syllabi has been the subject of debate for many years, the research conducted in this area over the last three decades has revealed that there seems to be wide agreement among theorists, translation instructors and practitioners that theory and practice should be part and parcel of translation training courses (Baker, 1992; Ingo, 1992; Pöchhacker, 1992; Hörmann, 1992; Munday, 2001; Calzada Pérez, 2005; Boase-Beier, 2010b). Such a changeover, in turn, indicates that the tug-of-war that once existed between the proponents and opponents of incorporating theory in designing translation syllabi has eased, resulting in a shift in perspective among those involved in translator training.

Consequently, many specialists started to raise and address questions like: (1) How can theory be useful to trainee translators?; (2) Why is theory useful to trainee translators?; (3) What are the theoretical aspects that should be included in translator training courses?; and (4) When should theory be introduced to translator training courses?.

On examining the answers to the first question, one notices that the proponents of the theory and practice approach maintain that theory can be useful in the training of translators under two conditions: (1) Theory and practice should be given equal weight when designing translation training courses; and (2) Theory has to be applied to the practical component of translation. This attitude to theory and practice is clearly emphasized by a number of scholars. Baker (1992, p. 2), for example, stated that the combination of theory and practice is needed in any academic course and elaborates that "theoretical knowledge is itself of no value unless it is firmly grounded in practical experience”. In the same vein, Gentile (1996), Munday (2001), Chesterman and Wagner (2002), and Fawcett and Guadarrama Garcia (2010) emphasized the importance of creating a balance between

\footnotetext{
1 The information about the University of Petra, the B.A. program in English/Arabic/English translation, and "Introduction to Translation" is applicable at the time of writing the paper.
} 
theory and practice in the teaching of translation, because these two components "both can flourish only if they feed each other continually” (Leuven-Zwart \& Naaijkens, 1991, p. 9). It is the author's contention that the symbiotic relationship that exists between theory and practice in teaching contexts is succinctly summarized by Boase-Beier (2010a) who stated that "theory opens out practice, allowing for innovation and experiment, and theory gives us a richer mental world with which to understand and discuss what we do" (p. xiii).

As far as the second question is concerned, many translation practitioners seem to be in agreement regarding the reasons why theory helps translators "to understand and discuss" what they do. They consider that theory "provides a framework of principles, restricted rules and hints for translation texts" (Newmark, 1982, p. 19); "it establishes principles to help us and our students to understand what being a translator really involves” (Ingo, 1992, p. 49); theories are also "tools because they are ways of seeing, and ways of seeing affect how we translate" (Boase-Beier, 2010a, p. xii); moreover, "translation theory can offer a set of conceptual tools. These can be thought of as aids for mental problem-solving” (Chesterman \& Wagner, 2002, p. 7). Such views indicate that theory is helpful and useful in the training of trainee translators, because it can act as a frame of reference that trainees can fall back on to guide and direct them regarding the choices and the decisions that have to be taken during the act of translation.

With regard to the nature of the theoretical input that is to be integrated in translation courses, practitioners have relied on a variety of theoretical concepts discussed in the field of Translation Studies in formulating this component. A selective overview of the literature on the theoretical base suggested for inclusion in translation classes is a clear manifestation of the diversity in approach adopted by practitioners. Some approaches underline the importance of linguistics and contrastive linguistics in the teaching of translation (Baker, 1992; Ibern, 1996, as cited in Calzada Pérez, 2005). The proponents of these approaches are of the belief that the concepts tackled under the rubric of the two domains offer students useful insights that can guide their translation decisions. Other practitioners emphasize that the text should be given priority in translation classes because genre conventions vary depending on the text type which entails that trainee translators should take these conventions into consideration to be able to choose the most appropriate translation strategies depending on the text type(s) being translated (Hatim \& Mason, 1990; Hatim, 2001). A third group stresses the functional approach to translation whereby trainee translators are taught to view translation as "a purpose-driven activity" (Farahzad, Azhideh, \& Razmjou, 2010, p. 14). Another group of practitioners argue that they can use the corpus-based theory in translation training. Zanettin (1998), for example, explained how translation trainees can make use of comparable bilingual corpora "to acquire specific skills related to translation" (p. 13). Contrary to the former “unidirectional” approaches, Calzada Pérez (2005) and Gonzales Davies (2005) contended that when designing the theoretical constituent of a translation syllabus instructors should not only emphasize one or two theories of translation; rather, the theoretical content should introduce students "to a large number of theories" that can be of value to them when they start performing the actual translation activity. It seems that the amalgam of theories suggested by Calzada Pérez and Gonzales Davies, if based on sound selectivity criteria, should empower students with a variety of problem-solving strategies that could facilitate the translation process, and allow students to produce more "acceptable” TLTs (target language texts).

The intertwinement between theory and practice in translator training syllabi has inevitably raised the question "When should theory be introduced into translation classes?”. The diversified theoretical aspects 
discussed by practitioners for inclusion in translation course content reveals that students should be acquainted with theory during their course of study as trainee translators. Consequently, it is noticed that some practitioners have suggested syllabi that could be taught to a group of beginners (Ingo, 1992; Calzada Pérez, 2005), while others have designed the theoretical component with the advanced translator trainee in mind (Hatim \& Mason, 1997).

In the Arab world, there is growing awareness among scholars and translation instructors of the importance of integrating a theoretical component in the translation course content. Many scholars believe that some of the deficiencies prevalent in translator training programs (effete syllabi, traditional pedagogies, lack of course material, and mismatches between the graduates' translation competencies and the expectations of the workplace) could be overcome by embedding a theoretical component that would go hand in hand with the practical component (El-Shiyab, 1996; Emery, 2000; Gabr, 2002; Farghal, 2009; Alaoui, 2011; El Karnichi, 2012; Atari, 2012).

Many translation practitioners in the Arab world, like their counterparts world-wide, concur that translation theory is useful since it provides guidelines that assist practicing translators in making decisions. To El-Shiyab (1996), translation theory is "an aid to the translator; it helps him to capture the sense and the spirit of verbal and non-verbal elements in texts” (p. 173). Farghal (2009) considered that translation theory "refines” and "sharpens" trainee translators' ability to make translation decisions; translation theory, he added: "aims to perfect translation competence rather than create it” (p. 14). According to Farghal, translation theory can be beneficial to students who exhibit some degree of translation competence.

Although many scholars acknowledge the importance of theory in translation training, the literature that discusses the kind of theory/theories suggested for incorporating in the theoretical input is limited, if one takes into consideration the proliferation of academic institutions that teach translation in the Arab world. It is also noted that not many instructors adopt or even refer to theory when they teach translation. Indeed, as Bahumaid (1995) rightly stated incorporating a carefully chosen theoretical input in Arab academic settings is of paramount importance, because "the lack of a theoretical component is yet another drawback in most Arab university undergraduate programs” (p. 99). In short, to be able to deal with the impediments facing translator training programs at Arab universities, the teaching community has to give theory the attention it deserves in curriculum design.

In their book Translation (1) (1996), Hajjaj and Farghal adopted a contrastive pedagogical approach addressed to "university students who are not initiated into translation" (p. i). Students are introduced to a number of "problematic" grammatical differences between Arabic and English at the sentence level, with the aim of equipping students with the knowledge needed to overcome grammatical difficulties encountered in the process of translation. Emery (2000) addressed "the notions of meaning and equivalence” (p. 107) in the theoretical component that he proposes. Other practitioners emphasize the importance of text-type in syllabus design. El-Shiyab (1996) and Hatim (1997) are of the viewpoint that the theoretical component in English/Arabic/English translation courses should familiarize students with the different genre conventions employed in different Arabic and English texts. Farghal and Shunnaq (2011) went a step further by focusing on two aspects, namely contrastive linguistics and text linguistics. The first part of the theoretical component pinpoints the grammatical differences between Arabic and English at the sentence level, whereas the second part discusses certain textual discrepancies noted in Arabic and English texts that students should bear in mind in the process of translation. Al-Qinai (2011) and El Karnichi (2012) confirmed that a multi-faceted theoretical component should be incorporated in translation courses. A theoretical component, that does not acquaint 
students with a particular concept, empowers them with the ability to choose from a number of options the strategies that are most suitable for the text(s) they are translating.

Like translation practitioners in other parts of the world, practitioners who teach English/Arabic/English translation have introduced a theoretical component in their syllabi that meets the needs of a wide spectrum of trainee translators. Some syllabi have been tailored for beginner trainee translators (Hajjaj \& Farghal, 1996), while others have been compiled for the advanced trainee translators (El-Shiyab, 1996; Emery, 2000; Hatim \& Mason, 1997). A third group has incorporated a theoretical component that follows a systematic progression whereby beginner and advanced students could benefit from the theoretical and practical components introduced in the same syllabus (Farghal \& Shunnaq, 2011).

Two features are characteristic of the approaches that adopt adding a theoretical input in translation syllabi: their universality and diversity. They are universal in that a plethora of scholars from different parts of the world have advocated embedding a theoretical component in designing translation syllabi. As far as diversity is concerned, a variety of concepts and issues discussed under translation theory are used to formulate the theoretical framework that best suits students' needs.

\section{A Multi-level Translation Syllabus}

\section{Rationale for a Multi-level Syllabus}

A basic argument in this paper has been that theory and practice should be treated as complementary rather than conflicting forces in translation teaching environments. In such a setup, theory empowers students with the strategies, guidelines, and techniques needed to help them make sound decisions when they start the actual process of translation (the practical component). By applying theory to practice, translation is transformed from a haphazard, intuitive activity into an activity that is based on certain parameters that aim at enhancing and facilitating the act of translation. When designing the "Introduction to Translation" syllabus, translation is compared to a jigsaw puzzle whose pieces can be successfully assembled by following a number of steps and problem-solving strategies (the picture on the box, the color of the pieces, the shape of the pieces, etc.). By the same token, to "put together" a workable target text, students must have a repertoire of problem-solving strategies that they can choose from in order to overcome the translation problems they encounter in the process of translation.

The multi-level syllabus was taught to 50 students who were registered in two different sections of the “Introduction to Translation” course during the second semester of the academic year 2011/2012; 24 students attended section 1 and 26 students attended section 2 . All of the students, with the exception of eight ${ }^{2}$, were second-year students doing translation for the first time. The students' GPA (Grade Point Average) was distributed as follows: 11 students had GPAs above 3, 27 students had GPAs between 2 and 3, and 12 students had GPAs below $2^{3}$.

Discussion with the students during the first contact hour revealed that they did not only know very little about translation but also that they had inaccurate information about this activity. Most of them were under the impression that translation is easy provided translators have "good" dictionaries to help them find the meanings of words. It was the author's responsibility to show students that translation does not merely involve a pen, a

2 The eight students were third-year students who had failed the course and were repeating it.

3 The University of Petra adopts a four-point GPA scale. 
paper, and a dictionary, and that it is a complex endeavor that needs rigorous training. Students were then given a short text to translate from English into Arabic; their translations reaffirmed that they did not know much about translation, for most of the translated Arabic texts were replicas of the English text, which resulted in an output that was "foreign" and difficult to comprehend.

The students' limited knowledge of what translation really involves confirmed the importance of integrating theory in the "Introduction to Translation" syllabus to complement the practical component.

Taking into consideration the students' linguistic competencies and their meagre knowledge of what translation involves, it is my contention that a multi-level syllabus should act as an eye-opener to the intricacies of translation, and should provide students with systematic guidelines that would enable them to make sound choices and decisions in the process of transferring a SLT (source language text) into a TLT.

\section{Designing and Implementing the Multi-level Syllabus}

To compile a multi-level syllabus for the "Introduction to Translation" course, Newmark's (1982) definition of theory is adopted. According to Newmark (1982), theory "provides a framework of principles, restricted rules and hints for translating texts and criticizing translations, a background for problem-solving" (p. 19), which is a perspective that befits the argument presented in this paper and allows students to relate the jigsaw puzzle metaphor to translation.

In designing the syllabus, a bottom-up approach is maintained because such an approach "is much easier to follow for those who have had no previous training in linguistics” (Baker, 1992, p. 6). The syllabus follows a progressive framework; it begins by introducing students to the preliminaries of translation; then, a number of fundamental issues at the lexical, linguistic, textual, and typological text levels are discussed and explained. Both theory and practice are emphasized in designing and teaching the syllabus. In the discussion of each level, the chosen theoretical issues are first explained to students; then, they are elucidated using authentic texts written in English and Arabic. Afterwards, students analyze texts that have been translated from English into Arabic to identify the strategies used in the act of translation.

After completing the theoretical component, students move on to the practical part. They have to translate selected texts from English into Arabic by applying the theoretical input examined in class. The practical component is conducted during classes, individually in groups, and after classes as take-home assignments. Students' translations are discussed and the strategies used to overcome translation problems are analyzed. Finally, an optimal version of the TLT is presented based on the discussion conducted in class. Thus, the pedagogical approach adopted not only gives theory and practice equal weight but aims at developing students' skills of observation, analysis, and problem-solving.

In what follows, an outline of the suggested syllabus and a brief explanation of how the contents are implemented in classes are provided.

Level 1-preliminaries. This introductory level tackles the basic principles of translation. It explains what translation work really involves to rectify the misconception(s) students have about translation. The following issues are discussed:

(1) Students are briefly introduced to the discipline of Translation Studies. Emphasis is given to the interplay between theory and practice. 
(2) The terms "translation" and "theory" are defined with reference to Newmark's (1982) approach. The comparison between translation and the jigsaw puzzle metaphor is introduced and explained so that students can visualize how theory can be applied to the practical component of translation.

(3) The following notions and terms are discussed: The different kinds of meaning (connotative meaning, denotative meaning, etc.) are explained using examples. Students have to realize from the very beginning that meaning is not a "simple" notion. The differences between "free" and "literal" translation are explained. Students are advised not to reproduce copies of the SLTs since motivated changes are accepted in translation. The terms "equivalence" and "non-equivalence" are explained using illustrative examples, and the importance of context is emphasized. Students are shown that context plays a key role in determining the most appropriate "equivalent". A number of examples are examined to illustrate this point.

(4) Culture and its impact on translation are pointed out. Students have to be aware that translation is not solely a linguistic activity, especially when the source and target languages are culturally very distant as is the case with Arabic and English. Strategies used in rendering cultural associations are briefly examined by referring to authentic translated examples.

(5) Students are briefly introduced to the concepts of textuality and text typology. They learn that translation involves rendering texts from one language into another and not sentences in isolation.

At this stage, students should come to grips with the fact that translation is not an "easy", "straightforward" activity, but one that involves a number of interrelated factors.

Level 2-lexical issues. Level 2 introduces students to some translation strategies that can help in overcoming specific lexical problems usually encountered by beginner trainee translators. The following points are emphasized:

(1) Dictionaries—students are introduced to the different kinds of dictionaries. Students discuss the limitations of dictionaries based on their personal experiences. The exercises that students have to complete in class reveal that dictionaries are merely translation aids which do not make them competent translators.

(2) Non-equivalence at the lexical level is underlined. Synonymy, antonymy, polysemy, hyponymy, meronymy, and selectional and collocational restrictions (Baker, 1992) are explained. Authentic translated texts are analyzed and students are introduced to the translation strategies used in solving lexical non-equivalence. The strategies identified include: omission, addition, redundancy, substitution, changing a specific noun into a general noun, and transliteration.

(3) Students translate selected excerpts that abound with lexical non-equivalents.

(4) The strategies used to render the non-equivalent lexical items are analyzed and students' translations are discussed.

After students are introduced to the second level, they should realize that competent translators cannot depend entirely on a "good" dictionary to solve all kinds of lexical translation problems.

Level 3-contrastive linguistics. The third level pinpoints the structural differences that beginner trainee translators usually find problematic when translating texts from English into Arabic. Teaching this level proceeds as follows:

(1) Students identify the basic structural dissimilarities between English and Arabic which they think can act as translation "hurdles". 
(2) The structural differences discussed in step 1 of Level 3, as well as other structures, are highlighted using illustrative examples taken from authentic English and Arabic texts. The incongruent structures highlighted include: articles, tenses, gender, number, word order, the active and passive voice, adjectives and adverbs, pre-modification and post-modification, and adjective and adverb clauses ${ }^{4}$.

(3) Translated texts are analyzed to identify the strategies employed in transferring the aforementioned incongruent structures from English into Arabic. Terms such as shifts, intra-system shifts, unit shifts, class shifts, structure shifts, marked and unmarked structures, explicitation, implicitation, naturalness, acceptability, and adequacy are briefly discussed.

(4) Students are asked to translate short texts and are reminded to take into consideration the theoretical issues discussed in levels 1-2. Students are advised to use these issues as problem-solving techniques to overcome the problems they encounter in the process of translation.

(5) Sample student translated texts are analyzed.

At this stage, it is expected that students should have acquired a repertoire of problem-solving strategies that would enable them to solve many of the basic lexical and grammatical problems encountered in the act of translation.

Level 4-text linguistics. In level 4, one standard of textuality, namely cohesion is discussed. Students are told that the lexical and grammatical aspects tackled in levels 2-3 only have "meaning potential in communicative events, that is, in text” (Baker, 1992, p. 111; emphasis original). Cohesion is chosen for two main reasons: (1) Students are introduced to this notion in the writing and reading courses they study before taking "Introduction to Translation"; and (2) Cohesion is considered by some theorists (Callow, 1974; Newmark, 1987; Baker, 1992) as one of the most important standards of textuality that could impart a negative impact on translated texts if transformed incorrectly. This level proceeds as follows:

(1) Cohesion is defined and the cohesive devices in English and Arabic are briefly explained. The different ways the two languages use the cohesive devices are exemplified (e.g., Arabic tolerates lexical repetition to connect sentences, while English prefers synonyms; Arabic uses the conjunction "waw" (and) frequently to connect sentences, whereas English does not use "and" as frequently, etc.).

(2) Texts translated by professional translators are analyzed to examine the strategies used in rendering these devices from English into Arabic.

(3) Students are asked to translate selected texts from English into Arabic, paying special attention to the translation strategies that need to be adopted in transforming the cohesive devices from English into Arabic. Students' translations are discussed and an optimal version is suggested based on the theoretical issues explained in levels 1-4.

By the time they finish the theoretical and practical constituents of level 4, students should be cognizant that when they translate a text from the SL (source language) to the TL (target language), a number of factors come into play: the lexical, the grammatical, and the textual. They should also be able to choose the most appropriate strategy/strategies in rendering these factors from the SL to the TL.

Level 5-text typology. In level 5, students are introduced to the notion of text types (the journalistic, the scientific, the legal, etc.). The following topics are discussed in level 5:

\footnotetext{
${ }^{4}$ Other grammatical differences encountered during the translation exercises are briefly explained during the correction process.
} 
(1) The notion of text types is briefly explained and a list of the basic text-forms is presented (the journalistic, legal, scientific, literary, etc.).

(2) Short text samples that illustrate the differences between the rhetorical conventions used in a number of text types are briefly discussed.

(3) Students are informed that the text type emphasized in the course is the news report. This text-form is chosen, because "detached text types (e.g., reporting) are likely to be less demanding to process and to translate than the more involved text-types (e.g., counter arguing)” (Hatim, 2001, p. 180). Bearing in mind the students' linguistic competencies, this text-form seems the most appropriate to teach.

(4) The rhetorical conventions of news reporting in English and Arabic are discussed. Using illustrative examples, students identify the most prominent differences between the constituents of a news report in the two languages (headlines, news report).

(5) Translated news reports are examined to identify the strategies adopted in transferring the rhetorical conventions from English into Arabic.

(6) Students practice translating a number of news reports from English into Arabic, and their translations are discussed and corrected with reference to the translation strategies discussed in the preceding four levels.

When students complete level 5, they are expected to have accumulated a repertoire of strategies that should act as a frame of reference in overcoming many of the translation problems encountered in the actual process of translation. It is the author's contention that raising students' awareness of the strategies discussed in the preceding levels should limit the "intuitive" nature of translation, and should make translation a challenging and thought-provoking activity.

\section{Students' Evaluation of the Multi-level Syllabus}

This section investigates students' attitudes concerning the effectiveness of embedding a theoretical input to complement the practical component in a beginner trainee translation syllabus. To fulfill this goal, a multiple choice questionnaire, written in Arabic, and consisting of 10 questions was prepared. To avoid confusing students, only three distracters were used: "Yes", "Slightly", and "No". After testing the questionnaire's validity and reliability, it was distributed to the students on the last day of classes. By then, students had completed the course and could evaluate its content. Forty-nine students answered the questionnaire, because one student was absent on the day the questionnaire was administered ${ }^{5}$. Students were not asked to disclose their names, but had to specify their GPA. The author wanted to know whether or not students' academic achievement had an impact on the answers they provided.

The following steps were adopted in the analysis of the students' responses. First, the total number of responses was grouped according to students' GPAs. Second, the percentages for each GPA were calculated. Finally, the percentages for each response were calculated.

The analysis of the students' responses reveals that students found the integration of theory and practice useful. The analysis also indicates that giving theory and practice equal weight was welcomed by the majority of students. In what follows, the responses provided for the 10 questions are analyzed and discussed.

\footnotetext{
${ }^{5}$ This student had a GPA in the 2 to 3 range.
} 


\section{Question 1: Did you have prior knowledge about translation theory before taking "Introduction to}

\section{Translation”?}

The responses show that the majority of students had no idea about translation theory before taking "Introduction to Translation" since 41 students out of 49 chose "No"; the remaining eight students chose "Slightly" (see Table 1). The GPAs of the students, who opted for the latter answer, indicate that they were most probably the ones who had failed the course and were repeating it again. After asking the member of staff who taught the course the previous semester about the syllabus content, she indicated that she had mentioned en passant that the discipline of Translation Studies emphasizes theory as well as practice. However, she focused on the practical component, because she was of the viewpoint that theory should be taught to advanced trainee translators.

Since (84\%) of the students had no previous knowledge of translation theory, this means that their evaluation of the syllabus is based on first-hand experience. Accordingly, the answers provided for the remaining nine questions should reveal to what extent they found incorporating theory and practice useful in the act of translation.

Table 1

Students' Responses to Question 1

\begin{tabular}{ccccccccc}
\hline Question 1 & Yes & Slightly & No & \multicolumn{2}{c}{ Percentage (\%) per GPA } & \multicolumn{2}{c}{ Percentage (\%) per response } \\
\hline \multicolumn{1}{c}{} & & & Yes & Slightly & No & Yes & Slightly & No \\
\hline GPA & & & & & & & & \\
$<2$ & 0 & 6 & 6 & 0 & 50 & 50 & 0 & 16 \\
2 to 3 & 0 & 2 & 24 & 0 & 8 & 92 & & 84 \\
$>3$ & 0 & 0 & 11 & 0 & 0 & 100 & & \\
\hline
\end{tabular}

Question 2: Before taking the course, were you aware of the role theory plays in solving translation problems?

This question was asked to ensure the reliability of the responses provided for Question 1. The students' answers substantiate that their background knowledge about translation theory was non-existent. This is the case, because 46 (94\%) students chose "No", indicating that they were unaware of the role theory plays in solving translation problems. The remaining three students (6\%), who chose "Slightly", were most probably those repeating the course (see Table 2). The responses show that out of the eight students who chose "Slightly" as an answer to Question 1, only three stated they knew how theory is used to solve translation problems. This reiterates that the member of staff who taught them the course did not focus on the interplay between theory and practice in translation.

Table 2

Students' Responses to Question 2

\begin{tabular}{|c|c|c|c|c|c|c|c|c|c|}
\hline \multirow[t]{2}{*}{ Question 2} & \multirow[t]{2}{*}{ Yes } & \multirow[t]{2}{*}{ Slightly } & \multirow[t]{2}{*}{ No } & \multicolumn{3}{|c|}{ Percentage (\%) per GPA } & \multicolumn{3}{|c|}{ Percentage (\%) per response } \\
\hline & & & & Yes & Slightly & No & Yes & Slightly & No \\
\hline \multicolumn{10}{|l|}{ GPA } \\
\hline$<2$ & 0 & 2 & 10 & 0 & 17 & 83 & \multirow{3}{*}{0} & \multirow{3}{*}{6} & \multirow{3}{*}{94} \\
\hline 2 to 3 & 0 & 1 & 25 & 0 & 4 & 96 & & & \\
\hline$>3$ & 0 & 0 & 11 & 0 & 0 & 100 & & & \\
\hline
\end{tabular}




\section{Question 3: Did you find the theoretical component taught useful?}

It is interesting to note that the majority of students found the theoretical component useful, for 46 chose "Yes" (94\%) ; two students chose "Slightly” (4\%), and one student chose "No” (2\%). This overwhelming majority reveals that the students, irrespective of their GPAs, benefitted from the theoretical component (see Table 3). Such a result is a clear indication that theory should not be considered an embellishment in beginner trainee translation courses; rather, it should be emphasized, and given due attention.

Table 3

Students' Responses to Question 3

\begin{tabular}{ccccccccc}
\hline Question 3 & Yes & Slightly & No & \multicolumn{2}{c}{ Percentage (\%) per GPA } & \multicolumn{2}{c}{ Percentage (\%) per response } \\
\hline \multicolumn{1}{c}{ GPA } & & & Yes & Slightly & No & Yes & Slightly & No \\
$<2$ & 9 & 2 & 1 & 75 & 17 & 8 & & 4 \\
2 to 3 & 26 & 0 & 0 & 100 & 0 & 0 & 94 & \\
$>3$ & 11 & 0 & 0 & 100 & 0 & 0 & & \\
\hline
\end{tabular}

Question 4: Do you think that the theoretical component covered was sufficient to help solve many of the translation problems encountered in the process of translation?

Thirty-three students (67\%) indicated that the theoretical component covered was sufficient since they chose "Yes" as an answer, while 16 chose "Slightly" (33\%); none of the students chose "No". It has to be mentioned that the students who chose "Yes" had different GPAs. Eight had GPAs above 3; 19 had GPAs between 2 and 3; and six had GPAs below 2 (see Table 4). If the total number of students in each GPA category is taken into consideration (11, 26, and 12 respectively), it is noted that a wide spectrum of students that exhibit different linguistic competencies applied the theoretical component taught while translating and found that it had equipped them with the strategies needed to overcome the translation problems they had encountered in the act of translation. The fact that none of the students chose "No" as an answer is yet another indication that the theoretical issues covered had fulfilled the goal they were intended to achieve.

Table 4

Students' Responses to Question 4

\begin{tabular}{|c|c|c|c|c|c|c|c|c|c|}
\hline \multirow[t]{2}{*}{ Question 4} & \multirow[t]{2}{*}{ Yes } & \multirow[t]{2}{*}{ Slightly } & \multirow[t]{2}{*}{ No } & \multicolumn{3}{|c|}{ Percentage (\%) per GPA } & \multicolumn{3}{|c|}{ Percentage (\%) per response } \\
\hline & & & & Yes & Slightly & No & Yes & Slightly & No \\
\hline \multicolumn{10}{|l|}{ GPA } \\
\hline$<2$ & 6 & 6 & 0 & 50 & 50 & 0 & \multirow{3}{*}{67} & \multirow{3}{*}{33} & \multirow{3}{*}{0} \\
\hline 2 to 3 & 19 & 7 & 0 & 73 & 27 & 0 & & & \\
\hline$>3$ & 8 & 3 & 0 & 73 & 27 & 0 & & & \\
\hline
\end{tabular}

Question 5: Were the theoretical and practical components given equal weight in designing and teaching the course?

This question was asked to test to what extent students agree or disagree that theory and practice were given equal weight in designing and implementing the course content of “Introduction to Translation”. Out of 49 
students, 46 chose "Yes" which confirms that students were of the belief that both components were equally emphasized (94\%); only three chose "Slightly" (6\%). This result asserts that one of the arguments introduced in this paper has been maintained (see Table 5).

Table 5

Students' Responses to Question 5

\begin{tabular}{|c|c|c|c|c|c|c|c|c|c|}
\hline \multirow[t]{2}{*}{ Question 5} & \multirow[t]{2}{*}{ Yes } & \multirow[t]{2}{*}{ Slightly } & \multirow[t]{2}{*}{ No } & \multicolumn{3}{|c|}{ Percentage (\%) per GPA } & \multicolumn{3}{|c|}{ Percentage (\%) per response } \\
\hline & & & & Yes & Slightly & No & Yes & Slightly & No \\
\hline \multicolumn{10}{|l|}{ GPA } \\
\hline$<2$ & 10 & 2 & 0 & 83 & 17 & 0 & \multirow{3}{*}{94} & \multirow{3}{*}{6} & \multirow{3}{*}{0} \\
\hline 2 to 3 & 25 & 1 & 0 & 96 & 4 & 0 & & & \\
\hline$>3$ & 11 & 0 & 0 & 100 & 0 & 0 & & & \\
\hline
\end{tabular}

Question 6: Would you have preferred giving the practical component more emphasis?

Thirty students (61\%) would have preferred giving more emphasis to the practical component since they chose "Yes"; the remaining 19 responses were distributed as follows: five students chose "Slightly" (10\%) and 14 chose "No" (29\%) (see Table 6). Students' willingness to give more emphasis to the practical component might be attributed to the fact that the theory taught throughout the semester helped students overcome the translation problems they had encountered; consequently, the practical component was not considered a frustrating activity since the "hurdles" experienced during translation could be solved using the strategies discussed in class.

Table 6

Students' Responses to Question 6

\begin{tabular}{|c|c|c|c|c|c|c|c|c|c|}
\hline \multirow[t]{2}{*}{ Question 6} & \multirow[t]{2}{*}{ Yes } & \multirow[t]{2}{*}{ Slightly } & \multirow[t]{2}{*}{ No } & \multicolumn{3}{|c|}{ Percentage (\%) per GPA } & \multicolumn{3}{|c|}{ Percentage (\%) per response } \\
\hline & & & & Yes & Slightly & No & Yes & Slightly & No \\
\hline \multicolumn{10}{|l|}{ GPA } \\
\hline$<2$ & 11 & 1 & 0 & 92 & 8 & 0 & \multirow{3}{*}{61} & \multirow{3}{*}{10} & \multirow{3}{*}{29} \\
\hline 2 to 3 & 10 & 3 & 13 & 38 & 12 & 50 & & & \\
\hline$>3$ & 9 & 1 & 1 & 82 & 9 & 9 & & & \\
\hline
\end{tabular}

\section{Question 7: Would you have preferred giving the theoretical component more emphasis?}

The majority of students did not think that the theoretical component needs to be given more weight in a beginner trainee translation course. In fact, 33 students (68\%) chose “No"; eight (16\%) chose "Slightly"; and the eight (16\%) who chose "Yes" had GPAs above 3 (see Table 7). The answers to this question confirm that students' responses to Question 4 were not haphazard since the majority of students stated, when they answered this question, that they had found the theoretical component covered sufficient in helping them solve the translation problems they faced when they worked on the practical component. One may infer that, since these students are beginner trainee translators, their limited knowledge of the diversified translation problems that translators are bound to come across, could have been the underlying reason for believing that additional theoretical issues need not be highlighted. 
Table 7

Students' Responses to Question 7

\begin{tabular}{ccccccccc}
\hline Question 7 & Yes & Slightly & No & \multicolumn{2}{c}{ Percentage (\%) per GPA } & \multicolumn{2}{c}{ Percentage (\%) per response } \\
\hline GPA & & & & Yes & Slightly & No & Yes & Slightly \\
\hline$<2$ & 0 & 2 & 10 & 0 & 17 & 83 & & \\
2 to 3 & 0 & 4 & 22 & 0 & 15 & 85 & 16 & 16 \\
$>3$ & 8 & 2 & 1 & 73 & 18 & 9 & & 68 \\
\hline
\end{tabular}

Question 8: Was the theoretical component taught always referred to when discussing students' translation errors?

This question tests whether students had become aware of the interplay between theory and practice. The responses reveal that all the students, with the exception of one, agreed that the theoretical component was always referred to when discussing students' translation errors (see Table 8). Such a result indicates that students had come to grips with the fact that theory and practice are the "recto and verso" of each other (Bhabha, 2004, as cited in Fawcett \& Guadarrama Garcia, 2010, p. 6).

Table 8

Students' Responses to Question 8

\begin{tabular}{ccccccccc}
\hline Question 8 & Yes & Slightly & No & \multicolumn{2}{c}{ Percentage (\%) per GPA } & \multicolumn{2}{c}{ Percentage (\%) per response } \\
\hline \multicolumn{1}{c}{ GPA } & & & Yes & Slightly & No & Yes & Slightly & No \\
\hline 2 & 12 & 0 & 0 & 100 & 0 & 0 & & 2 \\
2 to 3 & 25 & 1 & 0 & 96 & 4 & 0 & 98 & 0 \\
$>3$ & 11 & 0 & 0 & 100 & 0 & 0 & & \\
\hline
\end{tabular}

Question 9: Based on the syllabus taught in "Introduction to Translation”, do you think theory and practice should both be emphasized in all the translation courses offered by the English Department?

There was unanimous agreement among students that theory and practice should be emphasized in all the translation courses offered by the English Department. In fact, 48 students chose "Yes", and the remaining student chose "Slightly" (see Table 9). The distribution of responses confirms the need to incorporate theory in all the practical translation courses instead of confining this component to the purely theoretical courses.

Table 9

Students' Responses to Question 9

\begin{tabular}{ccccccccc}
\hline Question 9 & Yes & Slightly & No & \multicolumn{2}{c}{ Percentage (\%) per GPA } & \multicolumn{2}{c}{ Percentage (\%) per response } \\
\hline GPA & & & Yes & Slightly & No & Yes & Slightly & No \\
$<2$ & 11 & 1 & 0 & 92 & 8 & 0 & & 2 \\
2 to 3 & 26 & 0 & 0 & 100 & 0 & 0 & 98 & 0 \\
$>3$ & 11 & 0 & 0 & 100 & 0 & 0 & & \\
\hline
\end{tabular}


Question 10: Did the "Introduction to Translation” syllabus make you change your perspective towards translation and translating?

At the beginning of the course, most of the students were under the impression that translation is an activity that can be conducted successfully with the help of a "good" dictionary. This question considers whether students have changed the way they look at translation after completing the course. All the students expressed that they had changed their perspective towards translation and translating (see Table 10). This result shows that teaching theory and applying it to the practical component was an eye-opener for students; the proposed syllabus had participated in providing them with a "realistic" idea about the activity of translation.

Table 10

Students' Responses to Question 10

\begin{tabular}{|c|c|c|c|c|c|c|c|c|c|}
\hline \multirow[t]{2}{*}{ Question 10} & \multirow[t]{2}{*}{ Yes } & \multirow[t]{2}{*}{ Slightly } & \multirow[t]{2}{*}{ No } & \multicolumn{3}{|c|}{ Percentage (\%) per GPA } & \multicolumn{3}{|c|}{ Percentage (\%) per response } \\
\hline & & & & Yes & Slightly & No & Yes & Slightly & No \\
\hline \multicolumn{10}{|l|}{ GPA } \\
\hline$<2$ & 12 & 0 & 0 & 100 & 0 & 0 & \multirow{3}{*}{100} & \multirow{3}{*}{0} & \multirow{3}{*}{0} \\
\hline 2 to 3 & 26 & 0 & 0 & 100 & 0 & 0 & & & \\
\hline$>3$ & 11 & 0 & 0 & 100 & 0 & 0 & & & \\
\hline
\end{tabular}

\section{Conclusions}

Many translation theorists and scholars have recently realized the importance of integrating a theoretical component when teaching translation to trainee translators. This paper argues that theory and practice should go hand in hand when designing a translation syllabus for beginner trainee translators. The theory taught in the proposed syllabus is supposed to provide students with the strategies needed to help them overcome the translation problems they encounter in the translation process. To achieve this goal, a multi-level syllabus, that takes into consideration the students' linguistic competencies, is designed. Students are taught to apply the theoretical issues to the practical component of the course. The syllabus gives theory and practice equal weight and makes translation a challenging, thought-provoking, and problem-solving activity.

To assess the effectiveness of the syllabus, students are given a questionnaire whereby they express their viewpoints regarding the usefulness of integrating a theoretical component in a beginner trainee translation course. The students' responses reveal that they found the theoretical component useful, and that it has made them change their perspective towards translation and translating. The effectiveness of the proposed syllabus is also evident in students' responses that indicate the need to incorporate theory in all the translation courses offered by the English Department at the University of Petra.

The students' feedback reveals that theory and practice should be considered complementary rather than conflicting factors when designing trainee translation syllabi. Therefore, if an equilibrium exists between theory and practice, students' translation choices should be based on a sound theoretical background; this end-result is expected to limit the "intuitive" nature associated with the teaching of translation noted in many of the B.A. translation programs offered at universities in the Arab world. 


\section{References}

Alaoui, A. (2011). The teaching of translation in Moroccan universities. Retrieved from http://www.atida.org/english/index.php?option

Al-Qinai, J. (2011). Training tools for translators and interpreters. Jordan Journal of Modern Languages and Literature, 3(1), 19-38.

Atari, O. (2012). Impediments to translator training at Arab Universities: Proposal for change. Arab World English Journal (AWEJ), 3(1), 19-38. Retrieved from http://www.awej.org/awejfiles/-94-11.6.pdf

Bahumaid, S. (1995). On the teaching of translation at the University level. Turjumān, 4(2), 95-104.

Baker, M. (1992). In other words: A coursebook on translation. London and New York: Routledge.

Boase-Beier, J. (2010a). Preface. In A. Fawcett, K. L. Guadarrama Garcia, \& R. Hyde Parker (Eds.), Translation: Theory and practice in dialogue (pp. xi-xiii). London and New York: Continuum International Publishing Group.

Boase-Beier, J. (2010b). Who needs theory?. In A. Fawcett, K. L. Gaudarrama Garcia, \& R. Hyde Parker (Eds.), Translation: Theory and practice in dialogue (pp. 25-38). London and New York: Continuum International Publishing Group.

Callow, K. (1974). Discourse considerations in translating the word of God. Michigan: Zondervan.

Calzada Pérez, M. (2005). Applying translation theory in teaching. New Voices in Translation Studies, 1, 1-11. Retrieved from http://www.iatis.org/images/stories/publications

Chesterman, A., \& Wagner, E. (2002). Can theory help translators: A dialogue between the ivory tower and the wordface. Manchester: St. Jerome.

El Karnichi, F. (2012). Issues in advanced translator training programmes at Moroccan Universities. Retrieved from http://www.atida.org/english/index.php/option

El-Shiyab, S. (1996). The importance of teaching translation theory. Babel, 42(3), 166-173.

Emery, P. (2000). Introduction to translation theory and contrastive textology in Arab university translation courses. International Journal of Arabic-English Studies (IJAES), 1(1), 105-113.

Farahzad, F., Azhideh, P., \& Razmjou, L. (2010). Translator quality and awareness of functional translation theories. Iranian Journal of Applied Language Studies, 2(1), 1-16.

Farghal, M. (2009). Basic issues in translator training with special reference to Arab universities. International Journal of Arabic-English Studies (IJAES), 1(1), 105-113.

Farghal, M., \& Shunnaq, A. (2011). Translation with reference to English and Arabic: A practical guide. Irbid: Dar Al-Hilal for Translation.

Fawcett, A., \& Guadarrama Garcia, K. L. (2010). Introduction. In A. Fawcett, K. L. Guadarrama Garcia, \& R. Hyde Parker (Eds.), Translation: Theory and practice in dialogue (pp. 1-14). London and New York: Continuum International Publishing Group.

Gabr, M. (2002). A skeleton in the closet: Teaching translation in Egyptian national universities. Translation Journal, 6(1). Retrieved from http://www.bokarlang.com/journal/19edu.htm

Gentile, A. (1996). Translation theory teaching: Connecting theory and practice. In C. Dollerup, \& V. Appel (Eds.), Teaching translation and interpreting 3: New horizons (pp. 55-62). Amsterdam and Philadelphia: John Benjamins.

Gonzales Davies, M. (2005). Minding the process, improving the product: Alternatives to traditional translator training. In M. Tennent (Ed.), Training for the new millennium: Pedagogies for translation and interpreting (pp. 67-82). Amsterdam and Philadelphia: John Benjamins.

Hajjaj, A., \& Farghal, M. (1996). Translation (1). Amman: Al-Quds Open University.

Hatim, B. (1997). English-Arabic/Arabic-English translation: A practical guide. London: Saqi Books.

Hatim, B. (2001). Teaching and researching translation. Harlow: Longman/Pearson Education Limited.

Hatim, B., \& Mason, I. (1990). Discourse and the translator. London: Longman.

Hatim, B., \& Mason, I. (1997). The translator as communicator. London and New York: Routledge.

Hörmann, P. (1992). Introducing theory in a course of translation: A Chilean case study. In C. Dollerup, \& A. Loddegaard (Eds.), Teaching translation and interpreting: Training, talent and experience (pp. 57-61). Amsterdam and Philadelphia: John Benjamins.

Ingo, R. (1992). Translation theory: Four fundamental aspects. In C. Dollerup, \& A. Loddegaard (Eds.), Teaching translation and interpreting: Training, talent and experience (pp. 49-56). Amsterdam and Philadelphia: John Benjamins. 
Leuven-Zwart, K. M., \& Naaijkens, T. (1991). Translation studies: The state of the art: Proceedings of the first James S. Holmes symposium on translation studies. Amsterdam and Atlanta: Rodopi.

Munday, J. (2001). Introducing translation studies: Theories and applications. London and New York: Routledge.

Newmark, P. (1982). Approaches to translation. Oxford and New York: Pergamon Press.

Newmark, P. (1987). The use of systemic linguistics in translation analysis and criticism. In R. Steele, \& T. Threadgold (Eds.), Language topics: Essays in honour of Micheal Halliday (pp. 293-303). Amsterdam and Philadelphia: John Benjamins.

Pöchhacker, F. (1992). The role of theory in simultaneous interpreting. In C. Dollerup, \& A. Loddegaard (Eds.), Teaching translation and interpreting: Training talent and experience. Amsterdam and Philadelphia: John Benjamins.

Shunnaq, A. (1998). The translation situation in Jordan and the role of the Jordan Translators' Association (JTA). In A. Shunnaq, C. Dollerup, \& M. Saraireh (Eds.), Issues in translation (pp. 107-115). Irbid and Amman: Irbid National University and Jordanian Translators' Association.

Zanettin, F. (1998). Bilingual corpora and the training of translators. Meta, 43(4), 616-630. 